\title{
Internationalization of the Curriculum Through Student-Led Climate Change Teaching Activity
}

\author{
Helen V. McGregor, ${ }^{1,2, a}$ Beth O'Shea, ${ }^{3}$ Chris Brewer, ${ }^{4}$ Pamela Abuodha, ${ }^{1}$ and Emma J. Pharo ${ }^{5}$
}

\begin{abstract}
Internationalization of the curriculum is important in today's globalized environment, with the increasingly interdisciplinary nature of complex issues, such as climate change, requiring students to think beyond their disciplinary and cultural boundaries. Here we introduce a novel cross-discipline and cross-country activity with the overall goal to expose students to an international environmental problem (climate change) that requires an awareness of different perspectives, so as to contribute to their development of responsible global citizenship through internationalization of the curriculum. Students studying in Australia and the United States of America completed an anonymous survey on their climate change perceptions, and then the students discussed the results via a live video link. The survey results provided the catalyst for students to reflect on the ecological impact of their different lifestyles. The students could demonstrate their critical thinking skills and develop cross disciplinary thinking by exploring the vexed issue of climate change science, perceptions, and culture. Overall, the survey was simple to implement and the tutorial was successful despite the different time zones. Our activity achieved the broader goal of internationalization of student learning and enhanced our students' ability to view problems from different angles and helped foster boundary-crossing skills. (C) 2014 National Association of Geoscience Teachers. [DOI: 10.5408/13-033.1]
\end{abstract}

Key words: curriculum internationalization, climate change perceptions, globalization, student-led learning

\section{INTRODUCTION}

Colleges and universities recognize the need to educate their students to be global citizens (Parker et al., 1999; Nussbaum, 2002), since many of society's most pressing issues transcend national boundaries (Falk, 1993; Parker et al., 1999; Kirkwood, 2001; Walker, 2006). Kevin Hovland, the director of global learning and curricular change at the Association of American Colleges and Universities posits that global learning should enable all students "to approach the world's challenges and opportunities from multiple perspectives and to wrestle with the ethical implications of differential power and privilege" (Hovland, 2009). As Nussbaum (2002) suggests, students should have the "ability to criticize one's own traditions"; be able to "think as a citizen of the whole world, not just some local region or group"; and be able to "imagine what it would be like to be in the position of someone very different from oneself."

Climate change is one such issue requiring students to think as global citizens, and research shows that learning to cross cultural and discipline boundaries equips students with the skills to tackle this and other complex problems in the environmental sciences (Bouwen and Taillieu, 2004; Spelt et al., 2009; Bangay and Blum, 2010; Burandt and Barth, 2010; Fortuin and Bush, 2010). Furthermore, meaningful engage-

Received 30 April 2013; revised 12 January 2014; accepted 18 February 2014; published online 2 September 2014.

${ }^{1}$ School of Earth and Environmental Sciences, University of Wollongong, Northfields Avenue, Wollongong, NSW 2522, Australia

${ }^{2}$ Research School of Earth Sciences, The Australian National University, Mills Road, Canberra, ACT, Australia

${ }^{3}$ Department of Marine Science and Environmental Studies, University of San Diego, 5998 Alcala Park, San Diego, California 92110-2492, USA

${ }^{4}$ Centre for Education Development, Innovation and Recognition, University of Wollongong, Wollongong, NSW, Australia

${ }^{5}$ School of Land and Food, University of Tasmania, Hobart, TAS, Australia ${ }^{a}$ Author to whom correspondence should be addressed. Electronic mail: helen.mcgregor@anu.edu.au. Tel.: +61 43289 7139. Fax: +61 261250738 ment with the issue of climate change requires skills in understanding interdependencies and uncertainty in socioecological systems, and an ability to think in an "anticipatory and cross-linked way" (Burandt and Barth, 2010).

Despite the recognition of its importance, the teaching and learning of boundary-crossing skills is still in its infancy (Spelt et al., 2009). These boundary-crossing skills require students to "change perspective, to synthesize knowledge of different disciplines, and to cope with complexity" (Spelt et al., 2009), and equip graduates to respond to a rapidly changing and diverse world (Bangay and Blum, 2010). The ability to change perspectives and look at problems from different angles may not naturally develop (Fortuin and Bush, 2010) but can be facilitated through internationalization of education and exposure to cultural diversity. Internationalization of the curriculum is "the incorporation of an international and intercultural dimension into the teaching and learning processes, support services and content of a program, course or unit of study to engage students with cultural and linguistic diversity and purpose fully develop their international and intercultural perspectives as professionals and citizens within a campus culture that recognizes and values cultural diversity" (Leask, 2007, p. 206). Colleges and universities are uniquely situated to provide a comparative perspective whereby graduates know enough about other nations and cultures to make sound decisions involving cross border issues (Bok, 2007).

In this paper we outline a survey and tutorial that brings together internationalization and boundary-crossing skills, allowing students from different cultures and countries to explore the vexed issue of climate change science perceptions. There is broad interest in understanding perceptions of climate change because research shows that public opinion (Leiserowitz et al., 2013; Head et al., 2014) can be quite skewed compared with the understanding of climate researchers (Doran and Zimmerman, 2009; Anderegg et al., 2010; Cook et al., 2013). USA young adults have similar 
TABLE I. Student responses (AUS $n=73$, USA $n=29$ ) to climate change survey. Questions with notable differences or interesting responses are in italic.

\begin{tabular}{|c|c|c|c|}
\hline Question Asked & Answers to Choose From & AUS Responses (\%) & USA Responses (\%) \\
\hline \multicolumn{4}{|l|}{ PART I } \\
\hline \multirow[t]{3}{*}{ 1. My country of residence is } & Australia & 90 & 0 \\
\hline & USA & 10 & 97 \\
\hline & Other & 0 & 3 \\
\hline \multirow[t]{5}{*}{ 2. My age is } & $15-20$ & 57 & 45 \\
\hline & $21-30$ & 38 & 55 \\
\hline & $31-40$ & 1 & 0 \\
\hline & $41-50$ & 3 & 0 \\
\hline & Above 50 & 0 & 0 \\
\hline \multirow[t]{2}{*}{ 3. I am } & Female & 45 & 76 \\
\hline & Male & 55 & 24 \\
\hline \multirow[t]{3}{*}{ 4. My intended major is } & Science & 85 & 48 \\
\hline & Non-science & 14 & 52 \\
\hline & Didn't answer & 1 & 0 \\
\hline 5. My intended minor is & \multicolumn{3}{|c|}{ Did not collate responses } \\
\hline \multirow{9}{*}{$\begin{array}{l}\text { 6. My primary method of travel to } \\
\text { University is by }\end{array}$} & Car - sole occupant & 29 & 21 \\
\hline & Car - car pool & 16 & 17 \\
\hline & Bicycle & 3 & 0 \\
\hline & Train & 9 & 0 \\
\hline & Bus/tram/trolley & 30 & 3 \\
\hline & Ferry & 0 & 0 \\
\hline & Walk or run & 12 & 7 \\
\hline & Live on campus & 0 & 52 \\
\hline & Didn't answer & 1 & 0 \\
\hline \multirow{3}{*}{$\begin{array}{l}\text { 7. When compared with pre-1800s } \\
\text { levels, do you think that mean global } \\
\text { temperatures have generally risen, } \\
\text { fallen, or remained relatively } \\
\text { constant? }\end{array}$} & Risen & 89 & 83 \\
\hline & Fallen & 1 & 0 \\
\hline & Remained constant & 10 & 17 \\
\hline \multirow{2}{*}{$\begin{array}{l}\text { 8. Do you think human activity is } \\
\text { a significant contributing factor in } \\
\text { changing mean global temperatures? }\end{array}$} & Agree & 90 & 83 \\
\hline & Disagree & 10 & 17 \\
\hline \multirow{5}{*}{$\begin{array}{l}\text { 9. Personally, do you think that } \\
\text { you are well-informed or not about } \\
\text { human induced climate change? }\end{array}$} & Very well informed & 3 & 3 \\
\hline & Well informed & 66 & 52 \\
\hline & Not very well informed & 29 & 41 \\
\hline & Not at all informed & 1 & 3 \\
\hline & Don't know & 1 & 0 \\
\hline \multirow{4}{*}{$\begin{array}{l}\text { 10. Climate change is an } \\
\text { unstoppable process, we cannot do } \\
\text { anything about it. }\end{array}$} & Totally agree & 7 & 3 \\
\hline & Tend to agree & 27 & 35 \\
\hline & Tend to disagree & 52 & 52 \\
\hline & Totally disagree & 14 & 10 \\
\hline \multirow{4}{*}{$\begin{array}{l}\text { 11. The seriousness of climate } \\
\text { change has been exaggerated. }\end{array}$} & Totally agree & 3 & 10 \\
\hline & Tend to agree & 32 & 38 \\
\hline & Tend to disagree & 47 & 45 \\
\hline & Totally disagree & 19 & 7 \\
\hline
\end{tabular}


TABLE I. continued.

\begin{tabular}{|c|c|c|c|}
\hline Question Asked & Answers to Choose From & AUS Responses (\%) & USA Responses (\%) \\
\hline \multirow{4}{*}{$\begin{array}{l}\text { 12. Emission of } \mathrm{CO}_{2} \text { (carbon dioxide) } \\
\text { has only a marginal impact on climate } \\
\text { change. }\end{array}$} & Totally agree & 3 & 3 \\
\hline & Tend to agree & 22 & 41 \\
\hline & Tend to disagree & 47 & 38 \\
\hline & Totally disagree & 29 & 17 \\
\hline \multirow{4}{*}{$\begin{array}{l}\text { 13. Fighting climate change can } \\
\text { have a positive impact on the } \\
\text { community. }\end{array}$} & Totally agree & 45 & 45 \\
\hline & Tend to agree & 45 & 52 \\
\hline & Tend to disagree & 10 & 3 \\
\hline & Totally disagree & 0 & 0 \\
\hline \multirow{10}{*}{$\begin{array}{l}\text { 14. How serious a problem do you } \\
\text { think climate change is at this } \\
\text { moment? On a scale from } 1 \text { to } 10,1 \\
\text { would mean that it is not a serious } \\
\text { problem at all and } 10 \text { would mean } \\
\text { that it is extremely serious. }\end{array}$} & 1 & 0 & 0 \\
\hline & 2 & 0 & 0 \\
\hline & 3 & 3 & 0 \\
\hline & 4 & 1 & 3 \\
\hline & 5 & 7 & 14 \\
\hline & 6 & 20 & 21 \\
\hline & 7 & 34 & 21 \\
\hline & 8 & 16 & 31 \\
\hline & 9 & 6 & 10 \\
\hline & 10 & 12 & 0 \\
\hline \multirow{10}{*}{$\begin{array}{l}\text { 15. How serious a problem do you } \\
\text { think climate change will be in } 50 \\
\text { years' time? On a scale from } 1 \text { to } 10, \\
1 \text { would mean that it is not a serious } \\
\text { problem at all and } 10 \text { would mean } \\
\text { that it is extremely serious. }\end{array}$} & 1 & 0 & 0 \\
\hline & 2 & 0 & 0 \\
\hline & 3 & 0 & 0 \\
\hline & 4 & 1 & 3 \\
\hline & 5 & 3 & 0 \\
\hline & 6 & 1 & 7 \\
\hline & 7 & 11 & 21 \\
\hline & 8 & 27 & 17 \\
\hline & 9 & 29 & 21 \\
\hline & 10 & 27 & 31 \\
\hline \multirow{3}{*}{$\begin{array}{l}\text { 16. The media portrays climate } \\
\text { change science in a responsible way. }\end{array}$} & Agree & 19 & 14 \\
\hline & Disagree & 58 & 59 \\
\hline & Don't know & 23 & 28 \\
\hline \multirow{3}{*}{$\begin{array}{l}\text { 17. My actions can make a difference } \\
\text { to reducing global anthropogenic carbon } \\
\text { emissions. }\end{array}$} & Agree & 78 & 97 \\
\hline & Disagree & 10 & 3 \\
\hline & Don't know & 12 & 0 \\
\hline
\end{tabular}

beliefs to the general population that climate change is occurring and that humans are responsible (Feldman et al., 2010). Reasons for differing perceptions amongst the general public include the "creeping" nature of climate change, poor communication of the complexities and uncertainties, a lack of trust, negative portrayal of climate science in the media, and perceptions of risk (Moser and Dilling, 2004; Leiserowitz, 2005; Tollefson, 2010; Hmielowski et al., 2014). An emerging thought relevant to this study is that cultural perspectives and personal experience also shape societal attitudes towards the issue of climate change (Editorial, 2010; Kahan, 2010; Ding et al., 2011; Myers et al., 2013), making the complicated climate change topic suitable for a cross-cultural, international exchange in the college curriculum.

The survey and tutorial were administered to undergraduate students from two different English-speaking countries: the University of Wollongong, Australia, and the University of San Diego, United States of America. The students completed an anonymous survey on their perceptions of climate change, followed by a calculation of their individual ecological footprint, and then discussed the survey results and the differences between the student cohorts via a live video link. 
TABLE I. continued.

\begin{tabular}{|c|c|c|c|}
\hline Question Asked & Answers to Choose From & AUS Responses (\%) & USA Responses (\%) \\
\hline \multicolumn{4}{|l|}{ PART II } \\
\hline \multirow{21}{*}{$\begin{array}{l}\text { 18. If everyone lived like you, how } \\
\text { many planet Earth's would be } \\
\text { needed to provide the resources (to } \\
\text { the nearest } 0.5 \text { Earths)? }\end{array}$} & 0.5 & 3 & 0 \\
\hline & 1 & 1 & 3 \\
\hline & 1.5 & 4 & 10 \\
\hline & 2 & 16 & 31 \\
\hline & 2.5 & 20 & 14 \\
\hline & 3 & 14 & 3 \\
\hline & 3.5 & 16 & 17 \\
\hline & 4 & 10 & 10 \\
\hline & 4.5 & 1 & 0 \\
\hline & 5 & 3 & 3 \\
\hline & 5.5 & 3 & 0 \\
\hline & 6 & 0 & 3 \\
\hline & 6.5 & 3 & 0 \\
\hline & 7 & 1 & 0 \\
\hline & 7.5 & 0 & 0 \\
\hline & 8 & 0 & 0 \\
\hline & 8.5 & 0 & 0 \\
\hline & 9 & 0 & 0 \\
\hline & 9.5 & 0 & 0 \\
\hline & 10 & 0 & 0 \\
\hline & $>10$ & 4 & 0 \\
\hline \multirow{3}{*}{$\begin{array}{l}\text { 19. Comparing students, just like } \\
\text { yourself, from Australia and the USA, } \\
\text { which group of students do you think } \\
\text { would have the higher 'Number of } \\
\text { Earths'? }\end{array}$} & $\begin{array}{l}\text { Australian students will have a higher } \\
\text { carbon footprint than students from } \\
\text { the USA }\end{array}$ & 11 & 0 \\
\hline & $\begin{array}{l}\text { Students from the USA will have a } \\
\text { higher carbon footprint than } \\
\text { Australian students }\end{array}$ & 63 & 83 \\
\hline & $\begin{array}{l}\text { Their carbon footprints will be about } \\
\text { the same }\end{array}$ & 26 & 17 \\
\hline
\end{tabular}

The goal of the survey/tutorial activity was to expose students to an international environmental problem (climate change) that requires an awareness of different perspectives (e.g., cultural, political, societal) so as to contribute to their development of responsible global citizenship through internationalization of the curriculum. For this reason, we report on the implementation of the activity as a learning exercise, rather than report on the survey finding per se. Specifically, this exercise was designed for students to achieve the following desired learning outcomes: (1) to reflect on their own perceptions of climate change, lifestyles and impacts on their ecological footprint, (2) to compare and contrast climate change perceptions with students from different countries, and (3) to reflect on broader questions of why there are differences between key stakeholder (e.g., government, public, scientist) views on climate change and how international perspectives might play a role in these differences.

The survey showed notable differences between the climate change perceptions of the student cohorts, and students asked insightful questions of each other during the live video link in order to understand the differences. The survey was simple to implement and has subsequently been rolled out to other classes at both institutions. The live video tutorial was challenging both in terms of technology and timing ( $18 \mathrm{~h}$ time difference between Australia and the USA) but ultimately provided a platform for students to demonstrate their critical thinking around climate change issues and left an impression on students far beyond the normal lecture experience.

\section{THE PEDAGOGICAL IMPORTANCE OF GLOBAL CITIZENSHIP}

The world is getting smaller, brought about by the globalizing effect of information technology (Oblinger, 2001), which allows people in different countries and different time zones to communicate and collaborate with each other. Education should transcend cross-cultural boundaries, and provide an inclusive learning environment from which students can learn and explore their beliefs about their own and other cultures and behaviors. Along 
with their discipline specific knowledge, students must acquire the "skills, qualities and attitudes needed to make positive, ethical contributions as citizens and professionals to their global, national and local communities" (Leask, 2011, p. 8). Internationalization in higher education can integrate an international perspective into teaching, research and/or service functions of a university or college (Knight, 1997).

Although past efforts to achieve internationalization focused on student mobility by bringing international students together on campus (Leask, 2009), adapting a curriculum to be delivered offshore (Leask, 2011) or on student exchange programs (Yang, 2002), there is currently an agenda in most universities to provide opportunities for the "nonmobile majority" (Leask, 2009, p. 3). Student experiences need not be limited to constraints brought about by geographical location, but can be extended to the global classroom, unrestrained by time or place. According to Oblinger (2001, p. 62) "what we can see depends to a significant degree on what we have learned to think about, to look for, and to expect'. Chickering and Braskamp (2009) suggest a number of strategies to help students develop global perspective including bringing cultural differences into the classroom through pedagogical techniques. As such, in the survey and tutorial outlined in this paper, the students' classroom became a global classroom, giving them the opportunity to liaise with students who, although English speaking, were from a culture different to their own.

\section{METHODS \\ Participants}

The climate change survey and tutorial could be implemented between any classes that include a climate change component. In the example described in this paper it was delivered to first year undergraduate students in 2010 at the University of Wollongong, Australia, (herein AUS) and students ranging from first to fourth year at the University of San Diego, USA (herein USA). Note that although we use the USA/AUS abbreviations our students are not necessarily representative of all students in the respective countries.

AUS students were enrolled in the introductory first year Science Faculty subject "Climate Change", which covers the climate system, effects of humans on climate, climate change impact, mitigation and adaptation. The course has run since 2009 , and in 2010 there were 83 students enrolled in the subject (83\% Australian; $45 \%$ female, $55 \%$ male; $57 \%$ 18-20 years old (yo), 38\% 21-30 yo; Table I). There are no prerequisites for the course and it is open to students from any Faculty across the University, however approximately $85 \%$ of the students declared an intended science major. In addition to participating in the joint survey, the 2010 AUS cohort also participated in a joint activity with third year Environmental Law, reinforcing the cross-disciplinary nature of climate change (Davison et al., 2012; Pharo et al., 2013; Davison et al., 2014) and its selection as the topic to assess awareness of student global citizenship.

The USA students (2010: $97 \%$ American; $76 \%$ female, $24 \%$ male; $45 \%$ 15-20 yo, 55\% 21-30 yo; Table I) were enrolled in "Introduction to Earth Systems", a 100-level introductory course offered by rotating geology professors from the Department of Marine Science and Environmental Studies. The course has no prerequisites and serves both science majors (48\% in 2010) and non-science majors (52\% in 2010), with the latter fulfilling either a physical science requirement for humanities, business, and economics majors, or a liberal studies requirement for those obtaining an education credential for high school or elementary teaching. The course explores the interconnectedness of Earth's spheres and introduces basic geologic principles such as plate tectonics, rocks and minerals, and geologic time. Climate change concepts are covered in a 3-4 wk series of lectures explaining global climate, Earth's energy balance, paleoclimatology and anthropogenic climate change.

\section{Procedure}

AUS students were given the survey in the first week of class and completed it online using eLearning software. USA students completed the survey in written form midway through the semester before the 3-4 wk climate change unit. This discrepancy in timing was planned so that both cohorts received the survey prior to significant exposure to climate change curriculum. The survey (Supplemental Appendix A) was split into two parts. In Part I, students were surveyed for demographic information, and on their perceptions of climate change. There were 16 questions in Part I, and several (5 out of the total 19) questions were taken directly from surveys in published studies (European Comission, 2008; Doran and Zimmerman, 2009). These questions were used to allow the possibility for comparison of attitude between the students' and different sectors of the population, and provided additional international perspectives by reporting results from European surveys. Part I of the survey took approximately $15 \mathrm{~min}$ to complete.

After completing Part 1 of the survey, students were then asked to calculate their "ecological footprint" using an online calculator (EPA Victoria, 2010a). The Personal Ecological Footprint Calculator (EPA Victoria, 2010a) calculates how much productive land is required to maintain a given individual's lifestyle, taking into account the level of consumption, energy usage, and waste generated in a given year, assuming current technology (EPA Victoria, 2005). Results are given in (1) "Number of Earths" required to provide the resources if every person on the planet lived that individual's lifestyle, (2) global hectares of productive land used to sustain that individual's lifestyle, (3) an estimate of the tons of carbon $\left(\mathrm{CO}_{2}\right)$ emitted as a result of the individual's lifestyle, and (4) a pie chart of the factors contributing to the individual's ecological footprint.

The EPA Victoria's Ecological Footprint Calculator was chosen because it asked questions about a wide range of possible sources of $\mathrm{CO}_{2}$ that may contribute to a person's emissions, measures a wider range of environmental impacts than just greenhouse gas emissions, and had an appealing interface. The EPA Victoria's Ecological Footprint is also aligned with the international Ecological Footprint Standards adopted in 2006 to ensure the credibility and consistency of footprint studies (Global Footprint Network, 2009, 2010). For consistency, both cohorts of students used this Ecological Footprint Calculator. Students took on average $30 \mathrm{~min}$ to calculate their footprint and were encouraged to bring along electricity bills to make the survey as accurate as possible.

Part II of the survey consisted of two questions. Students were asked to enter the "Number of Earths" that would be needed if every person on the planet had their lifestyle. This metric was calculated as part of the ecological footprint 
TABLE II. Tutorial Agenda.

\begin{tabular}{|l|}
\hline A. $10-15$ minutes opening discussion AUS only \\
\hline B. Opening \\
\hline a. Comparison of demographics \\
\hline C. Discussion: Students to ask questions of each other related to: \\
\hline a. The way they lived \\
\hline b. Climate change as a problem \\
\hline c. Their ecological footprints \\
\hline d. Perceptions of scientific consensus on climate science \\
\hline D. Final question and wrap up \\
\hline
\end{tabular}

output. An additional question asked "Which group of students they thought would have the higher ecological footprint, students from Australia or USA?" Part II of the survey was completed in approximately $5 \mathrm{~min}$.

Twelve weeks after the AUS students completed the survey, and one week after the USA students finished the survey the students met via Skype to discuss the survey results and the similarities and differences between the two student groups. This timing was necessary to accommodate the offsets in semester timing in both countries. For the AUS students participation in the discussion was voluntary. For the USA students participation was compulsory as they were given one class lecture off in lieu of the evening Skype discussion. There was an 18-h time difference between AUS and USA. For the AUS students the activity took place from 1:30-2:30 pm, during one of the AUS lecture timeslots, and a light lunch was provided. For the USA students the activity took place from 7:30-8:30 pm. Twelve students participated from AUS and 30 students participated from USA. For the AUS students the tutorial was run in the final week of session before exams, which, together with voluntary participation in the tutorial, likely influenced the turnout. To ensure these students were representative of the majority of students in the class (and not solely high caliber students) an analysis of their grades showed that of the 12 AUS students who did participate, they report a slightly higher mean grade (75 $\pm 4 \%$; approximately equivalent to US $\mathrm{B}+$ ) compared to the class average (70 $\pm 9 \%$; approximately equivalent to US B). The average grade for students in the USA class was a $B-(80 \pm 15 \%)$.

Approximately $30 \mathrm{~min}$ prior to the Skype tutorial USA students were given a graphical summary of the survey results and were asked to prepare questions to ask during the tutorial. Students were divided into groups of approximately five and asked to focus on results that (1) identified climate change as a problem, and (2) highlighted differences between answers from students in the two countries. Students spent approximately 20 min refining their questions and the most interesting questions were selected to be asked during the live Skype chat. AUS students were presented with the same graphical summary as the USA students 10-15 min ahead of the Skype tutorial, and were encouraged to devise questions to ask during the tutorial. Table II shows the tutorial agenda that was followed.

\section{OBSERVATIONS AND ASSESSMENT OF LEARNING OUTCOMES}

We investigated the validity of our propositions through the four lenses of (Brookfield, 2002): self, student, peer and the literature (Implications and Conclusions section). We provide an analysis of the activity through self-reflection on the activity from the perspective of teachers, through asking peers to evaluate the outcomes of the activity, asking students, and comparing our work with similar scholarship of teaching and learning.

\section{Student Responses}

At the beginning of the tutorial students were excited and apprehensive about how the joint tutorial would work and what they might learn from each other. The climate change attitude survey results gave the tutorial a focal point and proved an effective catalyst for discussions. The survey responses for the USA and AUS students (all students) are summarized in Table I. There were several points of difference amongst the students in terms of demographics (e.g., intended major, gender), lifestyles (e.g., transport to/

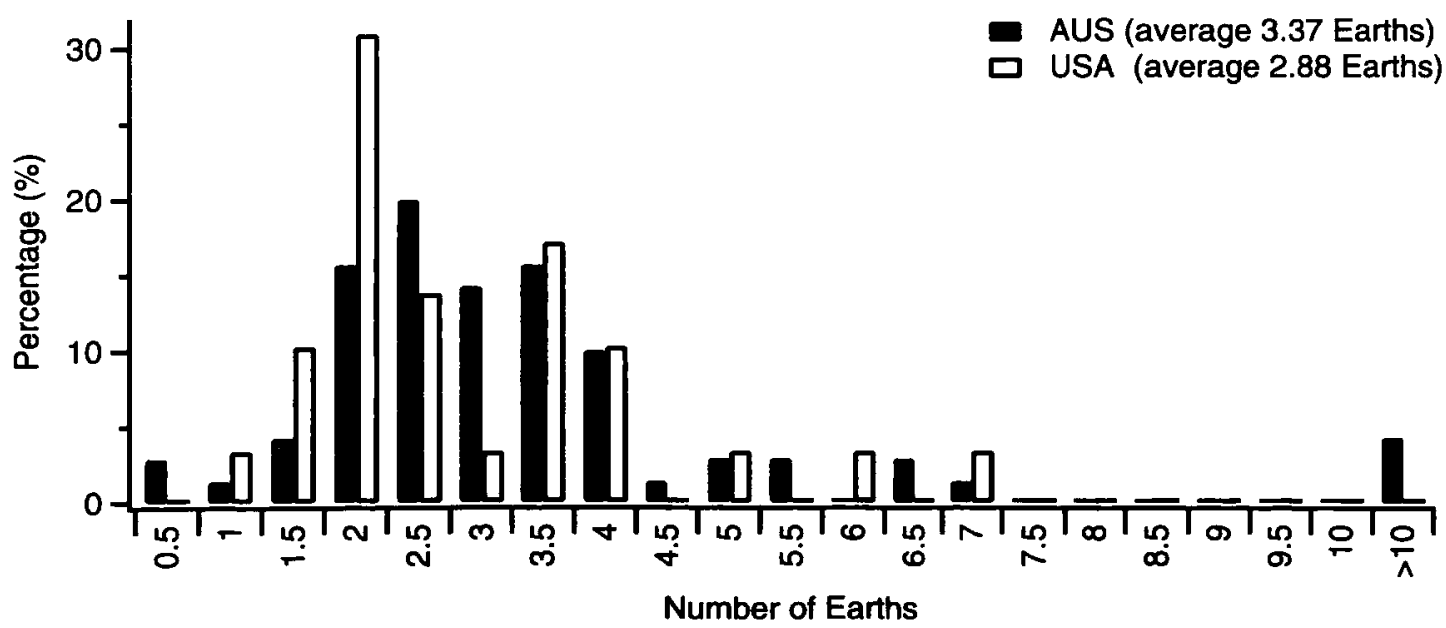

FIGURE 1. Comparison of the "Number of Earth" for AUS (grey) and USA (white) students who participated in the ecological footprint survey. The "Number of Earths" is a measure of the equivalent resources required if every person on the planet lived that individual's lifestyle (EPA Victoria, 2010b). 


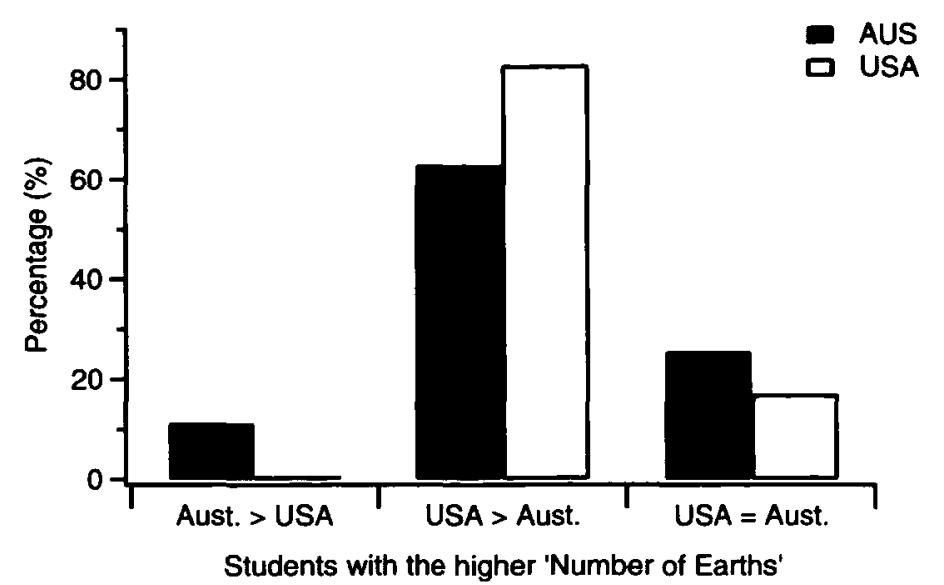

FIGURE 2. Comparison of the student's perception of which student cohort they believed would have the higher "Number of Earths". Most students, from either AUS (dark grey) or USA (white) perceived that students from the USA would require a greater "Number of Earths".

from campus), ecological footprint, and perceptions and attitudes in relation to climate change. Students were provided with a set of summary handouts drawing their attention to these points of difference.

Students commenced the discussion by asking questions about demographic differences between the cohorts. USA students were interested in the relatively low number of AUS students living on campus (52\% USA, 0\% AUS students living on campus; Table I), the relative size of the cities (San Diego and Wollongong) and their proximity to other major metropolitan centers (Los Angeles and Sydney, respectively). A key icebreaker was learning of the different legal drinking ages between the USA and AUS, and helped to open the discussion to international differences. In addition, questions and answers on vegetarianism and food origins, issues directly related to ecological footprints, and curiosity about the perception of each other's culture relaxed the students. More importantly, these opening discussions set the stage for students to begin reflecting on their own lifestyles and how such lifestyles might impact their ecological footprint (learning outcome one), which enabled the discussion to move towards comparing and contrasting each other's attitudes and perceptions towards climate change (learning outcome two). One AUS student asked:

"What do you think is your primary concern about climate change? What do you think will affect you the most?"

Rising oceans, loss of reefs and resources featured among the answers.

Another AUS student used her observations of wind farms in the Australian landscape to ask about wind farms and renewable energy usage in California. AUS students appeared surprised to hear that solar and wind energy were commonly used in California, highlighting a comparison between the two countries with respect to energy generation, but perhaps pointing out a contrast in the perception of the availability and use of such alternative energy. This then lead to a broader discussion of energy generation in each country.

A key aim of the learning outcomes was for students to reflect both on their own perceptions of, and consider any possible international differences in, their ecological footprints. Students were surprised that the USA students had a lower "Number of Earths" needed to sustain their lifestyle (2.88 USA and 3.37 AUS "Number of Earths"; Fig. 1) compared to the AUS students, especially since their perceptions of the other culture would have suggested otherwise (63\% AUS and $83 \%$ USA students thought USA students would have the higher "Number of Earths"; Table I and Fig. 2). The ensuing discussion, triggered by a question from a USA student showed depth, thought and insight: without prompting, students discussed possible flaws in the Footprint Calculator methodology, and possible reasons for the AUS outlier (Fig. 1). Collectively the students determined that the most likely reason for the difference may be from the transport footprint (Fig. 3). The students compared and contrasted their modes of transport to/from university, the duration of their commute, and broader social and financial reasons as to why students were living further or closer to

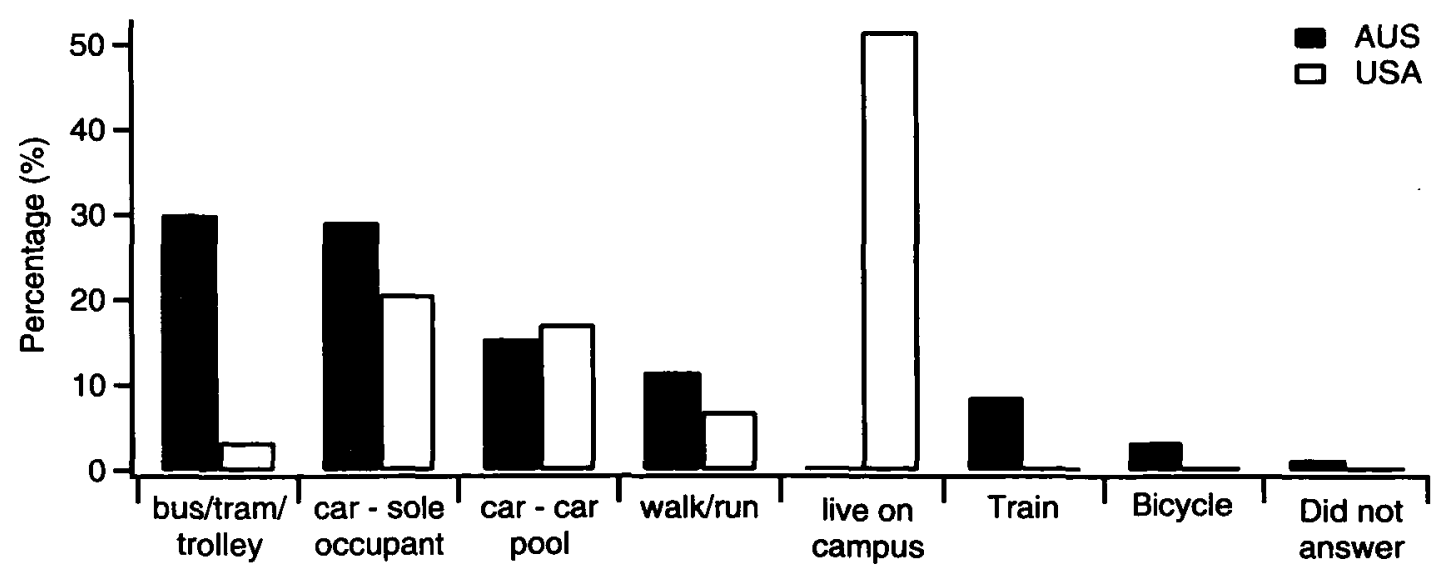

Transport method

FIGURE 3. Comparison of transport method for AUS (grey) and USA (white) students who participated in the ecological footprint survey. 
campus. They then discussed the implications of these choices for their ecological footprint.

To reflect on broader issues of culture and climate change and how differences may influence different stakeholder perspectives (learning outcome three), the students first started with questions focused on the individual perspective:

"Does your upbringing influence your attitudes to climate change?" (USA),

and broadened to consider other stakeholder perspectives with students discussing what factors may contribute to the large percentage of the public thinking that human activity is not a significant factor in changing mean global temperatures (Doran and Zimmerman, 2009).

The tutorial concluded with a spontaneous question from an AUS student:

"If they were going to do one thing individually, what do they think is the most important one thing that they could do to make a difference in regards to climate change?"

This prompted a deeper level of self-reflection from the students, all the more meaningful as it came from peers. Answers ranged from the practical behavioral changes (e.g., recycling, using less energy), to what they could do to influence global solutions (e.g., lobby politicians). The selfreflection was evident weeks later when USA students referred to the activity during fieldwork as part of their course, and the activity prompted a discussion of cultural differences and how that might relate to climate change attitudes. Furthermore, end-of-semester USA student evaluations of the entire course revealed the effectiveness of integrating an international perspective into the curriculum with students frequently mentioning their enjoyment of this particular part of the course. Hence the activity had a legacy beyond the classroom and appeared to meet the overall goal of the activity to increase globalization in the classroom.

\section{Teachers' Responses}

O'Shea (USA) and McGregor (AUS) observed similar interest and positive engagement from the AUS and USA students. In particular, O'Shea noted the development of more thoughtful and internationally relevant scientific questions as the discussion proceeded. Initially, student questions lacked focus, for example,

"Australian students seem to use public transport more, is it more reliable/accessible in Australia?"

"Since the ozone hole is close to Australia, do you have to wear more sunscreen?"

While these questions were useful for introductory discussions, the students were reminded of the purpose of the survey and the study in general, that is, to gain insights into possible perceptions and cultural differences they have regarding climate change. O'Shea suggested they use the demographic information as supplementary material to find a more focused question. As such, their second attempt at questions thus became more suitable in meeting the learning outcomes. For example,
"If Australian students generally feel more well informed regarding climate change, are they surprised to see that on average, Australian students have a higher ecological footprint than the American students?"

(question indicates that the student is contrasting the results of the ecological footprint between the two countries, in addition to investigating the perceptions of their own results).

"Are there any government policies in Australia that encourage environmental sustainability?"

(question indicates a broadening of the discussion to better understand how key stakeholders might be addressing an international problem such as climate change).

\section{PEER EVALUATION}

Two peers were asked for their evaluation of the exercise, the AUS course co-coordinator and an AUS Learning Designer. They agreed that the exercise had been a positive and engaging experience for students. The AUS co-coordinator of the subject, observed:

"Despite the difficulties [with video technology and time zone differences] both the students from AUS and USA were very enthusiastic in communicating with one another and soon it was as if the students had actually met each other before. The students not only asked each other questions related to climate change but also how they found university life and what they do during their free time."

AUS Learning Designer commented:

"The body language of the Wollongong Students was very positive. They gave indication that they felt involved, leaning toward the screen, and actively engaging not only with the USA students, but also with each other in response to some of the answers that the students provided. On exiting the room, one mature aged student commented that the activity had been great fun, and wished that there were more opportunities available to engage in this type of activity."

The AUS Learning Designer recommended that the AUS students have a longer discussion first, similar to the format of the USA, to focus them, and to discuss their own ecological footprints. Group participation in discussion can be one of a range of strategies to increase public understanding of climate science (Center for Research on Environmental Decisions, 2009). An additional suggestion was to have a discussion of key issues of climate change for both groups whereby the AUS and USA students formed mixed groups (though the AUS Learning Designer noted that this would be harder to implement).

\section{SUGGESTIONS AND IMPROVEMENTS FOR IMPLEMENTATION OF THE ACTIVITY Implementing the Climate Change Survey}

The climate change attitude survey is relatively simple to implement logistically, either as a paper-based or electronic survey, however wording of some questions, particularly 
related to demographic information, may need to be adapted to specific student cohorts. In our case, after conducting the survey in 2010 several questions were revised (Supplemental Appendix A gives the revised survey). For Australian students, an age category of less than 18 y was added as a significant number of students in first year are under this age. This is also helpful for U.S. institutions where Institutional Review Board ("ethics" approval) may be specific to adults $18 \mathrm{y}$ and over.

Question 5, on the student's mode of transport was made more specific. The original wording, "My primary method of travel to university is by...", was ambiguous. The new wording "My primary method of travel from my home (during the teaching semester) to class is..." (Supplemental Appendix A), focuses more on transport to and from campus during the teaching semester. The categories for responses to this question were simplified, and the "live on campus" category was removed.

Three new questions were added to the survey: "The approximate distance between my home (during the teaching semester) and campus is..."; "Fighting climate change can have a positive impact on the economy..."; "In your opinion, would you agree or disagree that there is general scientific agreement on human induced climate change?" (Supplemental Appendix A). The revised survey also asked for more information on declared minors, in addition to majors, to better understand the target audience. We would recommend implementing the revised survey.

The survey can be rolled out and adapted in a number of different ways. In 2011 the survey was given to students at the University of Wollongong in five different subjects and covering four different year levels. Students in the classes "Social and Environmental Accounting" (third year), "Redefining Eden: Indigenous Peoples and the Environment" (second year), "Communication and ICT Workplace Practice" (Masters level), "Fundamentals of Science Communication" (Masters level), and "Climate Change" (first year) all completed the survey. With student data from multiple disciplines and multiple year levels, it is possible to see discipline-specific differences in student perceptions of climate change. With the survey conducted in 2012 attitudinal differences through time can also be explored. Together, analyzing the survey results themselves can form a student activity, even without interaction with students from another class. Students can compare their own perceptions of climate change to students in other disciplines and surveys from previous years, reflect on the possible reasons for similarities and differences, and reflect on their own ecological footprints. Furthermore, because a number of the survey questions were taken from surveys of the general public and climate scientists it would be possible for the students to compare their results to results from these other populations.

There is a range of different tools for calculating ecological footprints. The implementation of this activity is not dependent on the choice of Ecological Footprint Calculator, but it is important that all students use the same Calculator. An additional dimension to the task could be to compare the results of different calculators.

\section{Implementing the Joint Tutorial}

The joint tutorial presents some logistical challenges. Issues of time zone differences, technology, and class size must all be considered. Mutually convenient time zones can be planned using simple web tools, such as http:// timeanddate.com/worldclock/meeting.html. Dedicated video conferencing facilities would be ideal, allowing a more free flowing discussion, although in this case Skype worked quite well. This activity would ideally suit classes of around 30 students, as any more than this number would make the full-class discussion unwieldy. Given that consideration, however, the activity is flexible enough that the discussion part of the tutorial could adopt a different format. For example, students could be broken into smaller groups, paired up between the classes and left to organize their own discussion.

Pedagogically, it was challenging to keep the joint tutorial educationally beneficial. The students were excited to talk to those from another culture. While this fits with the activity's goals of internationalization and cultural exposure, we needed them to focus to ask questions with substance that related directly to the activity goals. Providing the survey results to the students before the tutorial and asking them to devise and hand in possible questions to ask, as was done at USA, is one way to overcome this issue. Dedicated discussion facilitators (in our case McGregor and $\mathrm{O}^{\prime}$ Shea) can also keep the discussion focused.

\section{Metacognition}

We also recommend post-tutorial metacognition, either by class discussion, or by a short reflection assignment. Students should reflect on what they found most surprising or unclear, or what new insights they had gained. Students could compare along the lines of "I used to think. . . but now I know...". Furthermore students could reflect on ways in which the joint tutorial is or is not a good way to compare student cohorts.

Metacognition is also recommended for instances where the survey alone is implemented. In 2010 and where the survey was given in subsequent years (without tutorial), AUS students were required to compare their carbon footprint to consumption in other Australian demographics (e.g. http://www. acfonline.org.au/sites/default/files/resource/index67.swf ), and globally (e.g., http://carbonfootprintofnations.com/), and reflect on the inter-relation of income, consumption, and $\mathrm{CO}_{2}$ emissions. The students were asked to discuss the main contributions to their ecological footprints, and what can they could do to reduce their footprint. In addition, the students were asked to form small groups and discuss what they think they know and don't know about climate change; how they know what they know; the points of knowledge similarity and difference between them; how they would resolve the differences and investigating the evidence for/against their differing positions; the difference between "opinions" and "facts" in relation to the climate change debate; and, what they think may be reasons for confusion surrounding climate change science. These reflection topics are consistent with the learning outcomes of the survey/joint tutorial, and further could also be focal points for the joint tutorial.

\section{IMPLICATIONS AND OPPORTUNITES FOR FURTHER RESEARCH}

Reasons behind the student responses likely extend far beyond simple Australian versus American cultural traditions. For example, Kahan (2010) refers to cultural cogni- 
tion-the influence of group values on one's beliefs-to explain that the same groups of people who disagree on "cultural issues", such as abortion and same sex marriage, also disagree on whether climate change is real. While the present study did not aim to investigate such competing moral outlooks, the results provide preliminary thought into possible reasons for student responses. As such, we have included a summary of student responses to the survey in Table I. The more reflective student may be inspired to critically evaluate reasons for the variety of opposing responses, hopefully leading to a justification of their responses. This can be instrumental to establishing their own sense of identity (or group identity) and is a fundamental component of a student's progression towards developing a global perspective (Chickering and Braskamp, 2009). Our survey could be extended to delve into students' political and personal beliefs and compare these factors with nationality in terms of how well they predict student's responses.

The psychology behind students' responses may be of interest to those in the fields of geoscience cognition or environmental psychology. For example, one of the interesting questions/responses highlighted in the survey results (Table I) indicates that students in the United States (USA) more strongly recognize that their actions may make a difference to reducing global anthropogenic carbon emissions (question 17), when compared to the responses of the Australian students. This could be linked to broader questions of climate change perceptions, for example the work of Lewandowsky (2011), which showed that when graphs of upward trending temperatures was presented as share prices, people correctly judged the trend, irrespective of their attitude towards climate change.

\section{CONCLUSIONS}

The strength of this activity is that it makes use of available technology to bring internationalization to the classroom. Our activity teaches the students to think outside their discipline, encourages multidisciplinary thought, preparing them to tackle "tricky" problems and is flexible enough to be adapted to a variety of classroom settings. Consistent with the advice of (Murphy et al., 2005), our activity is constructivist, providing scaffolding for students to make sense of climate change decision-making through active learning.

Overall, the authors perceive that the activity was successful in achieving the learning outcomes and overall goal. Discussion between the two international cohorts successfully identified similarities and differences in their own (and others') perceptions of climate change, while also noting and reflecting on differences in lifestyle, culture, personal upbringing, and government policy that may influence climate change perceptions at different stakeholder levels. The results of these discussions and reflections indicate that students gain a greater appreciation for the role of globalization in addressing environmental problems. It is thus hoped that by designing a simple activity to internationalize the curriculum, student awareness of different international and cultural perspectives will help contribute to the successful development of responsible global citizens.

\section{ACKNOWLEDGMENTS}

The authors wish to thank U. San Diego graduate student Allison Yoshida for assistance in compiling the survey results, and the ALTC LNCC project members for thoughtful discussions. We especially acknowledge the enthusiasm of the students who participated in this activity. This research received funding from Australian Learning and Teaching Council (ALTC) grant \#LE9-1183. The research was carried out with ethics approval from the University of Wollongong (\#HE10/294), the University of Tasmania under the auspices of ALTC grant \#LE9-1183 (Ethics Reference: H11376), and University of San Diego Institutional Review Board approval (IRB project \#2012-08-224). HVM was supported by an Australian Institute of Nuclear Science and Engineering Fellowship and a Guest Researcher Fellowship from the Centre for Environmental and Climate Research, Lund University.

\section{REFERENCES}

Anderegg, W.R., Prall, J.W., Harold, J., and Schneider, S.H. 2010. Expert credibility in climate change. Proceedings of the National Academy of Sciences of the United States of America, 107:1210712109 .

Bangay, C., and Blum, N. 2010. Education responses to climate change and quality: Two parts of the same agenda? International Journal of Educational Development, 30:359-368.

Bok, D., 2007. Our underachieving colleges: A candid look at how much students learn and why they should be learning more. New York: Princeton University Press, p. 225-254.

Bouwen, R., and Taillieu, T. 2004. Multi-party collaboration as social learning for interdependence: Developing relational knowing for sustainable natural resource management. Journal of Community and Applied Social Psychology, 14:137-153.

Brookfield, S.D. 2002. Using the lenses of critically reflective teaching in the community college classroom. New Directions for Community Colleges, 2002:31-38.

Burandt, S., and Barth, M. 2010. Learning settings to face climate change. Journal of Cleaner Production, 18:659-665.

Center for Research on Environmental Decisions. 2009. The Psychology of Climate Change Communication: A Guide for Scientists, Joumalists, Educators, Political Aides, and the Interested Public. New York: Columbia University.

Chickering, A., and Braskamp, L.A. 2009. Developing a global perspective for personal and social responsibility. Peer Review, 11:27-30.

Cook, J., Nuccitelli, D., Green, S.A., Richardson, M., Winkler, B., Painting, R., Way, R., Jacobs, P., and Skuce, A. 2013. Quantifying the consensus on anthropogenic global warming in the scientific literature. Environmental Research Letters, 8:024024, DOI: $10.1088 / 1748-9326 / 8 / 2 / 024024$.

Davison, A., Brown, P., Pharo, E., Warr, K., McGregor, H., Terkes, S., Boyd, D., and Abuodha, P. 2014. Distributed leadership: innovation in university climate change teaching. International Journal of Sustainability in Higher Education, 15:98-110, DOI: 10. 1108/IJSHE-10-2012-0091.

Davison, A., Pharo, E., Warr, K., Abuodha, P., Boyd, D., Brown, P., Devereux, P., Egan, A., Hart, G., McGregor, H., Rooney, M., and Terkes, S. 2012. Demonstrating distributed leadership through cross-disciplinary peer networks: Responding to climate change complexity. Final Report Sydney: Australian Learning and Teaching Council.

Ding, D., Maibach, E.W., Zhao, X., Roser-Renouf, C., and Leiserowitz, A. 2011. Support for climate policy and societal action are linked to perceptions about scientific agreement. Nature Climate Change, 1:462-466, DOI: $10.1038 /$ NCLIMATE1295. 
Doran, P.T., and Zimmerman, M.K. 2009. Examining the scientific consensus on climate change. EOS Trans. AGU, 90:22-23.

Editorial 2010. Climate of suspicion. Nature, 463:269, DOI: 10.1038/ 463269a.

EPA Victoria. 2005. EPA ecological footprint calculators. Environmental Protection Authority State Government Victoria Technical background paper 972, p. 22. Available at http:// www.epa.vic.gov.au/our-work/publications/publication/2005/ february/972.

EPA Victoria. 2010a. Ecological footprint: Personal calculator. Available at http://www.epa.vic.gov.au/ecologicalfootprint/ calculators/personal/introduction.asp (accessed 4 December 2012).

EPA Victoria. 2010b. Ecological Footprint - about. Available at http://www.epa.vic.gov.au/ecologicalfootprint/about/default. asp (accessed 4 December 2012).

European Commission. 2008. Europeans' Attitudes Towards Climate Change. Brussels: Conducted by TNS Opinion \& Social, requested and coordinated by the European Commission and the European Parliament, Directorate-General for Communication of the European Commission.

Falk, R., 1993. The making of global citizenship. In Brecher, J., Childs, J.B., and Cutler, J., eds., Global visions: Beyond the new world order. Boston: South End Press.

Feldman, L., Nisbet, M.C., Leiserowitz, A., and Maibach, E. 2010. The Climate Change Generation? Survey analysis of the perceptions and beliefs of young Americans. Yale Project on Climate Change Communication, Yale University and George Mason University.

Fortuin, I.K.P.J., and Bush, S.R. 2010. Educating students to cross boundaries between disciplines and cultures and between theory and practice. International Joumal of Sustainability in Higher Education, 11:19-35.

Global Footprint Network. 2009. Ecological Footprint Standards 2009. Oakland, CA: Global Footprint Network, p. 17. Available at http://www.footprintstandards.org.

Global Footprint Network. 2010. Global Footprint Network: Frequently asked questions. Available at http://www. footprintnetwork.org/en/index.php/GFN/page/frequently_asked_ questions/ (accessed 4 December 2012).

Head, L., Adams, M., McGregor, H.V., Toole, S. 2014. Climate change and Australia. WIREs Climate Change, 5:175-197, DOI: 10.1002/wcc. 255 .

Hmielowski, J.D., Feldman, L., Myers, T.A., Leiserowitz, A., and Maibach, E. 2013. An attack on science? Media use, trust in scientists, and perceptions of global warming. Public Understanding of Science, in press. DOI: 10.1177/0963662513480091.

Hovland, D. 2009. Global learning: What is it? Who is responsible? Peer Review, 11:4-7.

Kahan, D. 2010. Fixing the communications failure. Nature, 463:296-297.

Kirkwood, T.F. 2001. Our global age requires global education: Clarifying definitional ambiguities. The Social Studies, 92:10-15, DOI: $10.1080 / 00377990109603969$.

Knight, J. 1997. A shared vision? Stakeholder's perspectives on internationalization of higher education in Canada. Journal of Studies in International Education, 1:27-44.
Leask, B. 2007. Intemationalisation of the curriculum: Making international education everyone's business. Available at http://aiec.idp.com/uploads/pdf/Leask \% 20Thu \% 200900 \%20B7.pdf (accessed 4 December 2012).

Leask, B. 2010. Beside me is an empty chair: the student experience of internationalisation, In Jones, E., ed., Internationalisation and the student voice: Higher education perspectives. New York: Routledge, p. 3-17.

Leask, B. 2011. Assessment, learning, teaching and internationalization-engaging for the future. Assessment, Teaching and Learning Journal (Leeds Met), 11:5-20.

Leiserowitz, A., Maibach, E., Roser-Renouf, C., Feinberg, G., and Howe, P. 2013. Climate change in the American mind: Americans' global warming beliefs and attitudes in April, 2013. Yale Project on Climate Change Communication. New Haven, CT: Yale University and George Mason University. Available at: http://environment.yale.edu/climate/files/ Climate-Beliefs-April-2013.pdf.

Leiserowitz, A.A. 2005. American risk perceptions: Is climate change dangerous? Risk Analysis, 25, DOI: 10.1111/j.1540$6261.2005 .00690 \mathrm{x}$.

Lewandowsky, S. 2011. Popular consensus climate change is set to continue. Psychological Science, 22:460-463.

Moser, S.C., and Dilling, L. 2004. Making climate hot: Communicating the urgency and challenge of global climate change. Environment, 46:32-46, DOI: 10.1080/00139150409605820.

Murphy, K.L., Mahoney, S.E., Chen, C.-Y., Mendoza-Diaz, N.V., and Yang, X. 2005. A constructivist model of mentoring, coaching, and facilitating online discussions. Distance Education, 26:341-366.

Myers, T.A., Maibach, E.W., Roser-Renouf, C., Akerlof, K., and Leiserowitz, A.A. 2013. The relationship between personal experience and belief in the reality of global warming. Nature Climate Change, 3:343-347, DOI: 10.1038/NCLIMATE1754.

Nussbaum, M. 2002. Education for citizenship in an era of global connection. Studies in Philosophy and Education, 21:289-303.

Oblinger, D. 2001. The world is getting smaller, but are we seeing farther? EDUCAUSE Review Magazine, 36:62-63.

Parker, W.C., Ninomiya, A., and Cogan, J. 1999. Educating world citizens: Toward multinational curriculum development. American Educational Research Journal, 36:117-145, DOI: 10.3102/ 00028312036002117.

Pharo, E., Davison, A., McGregor, H., Warr, K., and Brown, P. 2014. Using communities of practice to enhance interdisciplinary teaching: Lessons from four Australian institutions. Higher Education Research and Development, 33:341-354, DOI: 10.1080/ 07294360.2013 .832168

Spelt, E.J.H., Biemans, H.J.A., Tobi, H., Luning, P.A., and Mulder, M. 2009. Teaching and learning in interdisciplinary higher education: A systematic review. Educational Psychology Review, 21:365-378.

Tollefson, J. 2010. An erosion of trust? Nature, 466:24-26.

Walker, G., 2006. Introduction. In Walker, G., ed., Educating the global citizen. Saxmundham: John Catt Educational Ltd.

Yang, R., 2002. University internationalisation: Its meanings, rationales and implications. Intercultural Education, 13:81-95. 